\title{
Supporting Students with Autism in Tertiary Education: Malaysian Lecturers' Views and Experiences
}

\author{
Khairul Farhah Khairuddin",*, Siti Daniah Salleh², Aizan Sofia Amin³ \\ ${ }^{1}$ Faculty of Education, Universiti Kebangsaan Malaysia, 43600, Bangi, Malaysia \\ ${ }^{2}$ Pre-University and General Studies Section, German-Malaysian Institute, 43000, Kajang, Malaysia \\ ${ }^{3}$ Faculty of Science Social and Humanity, Universiti Kebangsaan Malaysia, 43600, Bangi, Malaysia
}

Received July 30, 2020; Revised October 7, 2020; Accepted October 30, 2020

\begin{abstract}
Cite This Paper in the following Citation Styles
(a): [1] Khairul Farhah Khairuddin, Siti Daniah Salleh, Aizan Sofia Amin, "Supporting Students with Autism in Tertiary Education: Malaysian Lecturers' Views and Experiences," Universal Journal of Educational Research, Vol. 8, No. 11A, pp. 1 - 8, 2020. DOI: 10.13189/ujer.2020.082101.
\end{abstract}

(b): Khairul Farhah Khairuddin, Siti Daniah Salleh, Aizan Sofia Amin (2020). Supporting Students with Autism in Tertiary Education: Malaysian Lecturers' Views and Experiences. Universal Journal of Educational Research, 8(11A), 1 - 8. DOI: 10.13189/ujer.2020.082101.

Copyright $\odot 2020$ by authors, all rights reserved. Authors agree that this article remains permanently open access under the terms of the Creative Commons Attribution License 4.0 International License

\begin{abstract}
The increasing pressure to provide inclusive and equitable education and promote lifelong learning for all has enabled a growing number of individuals with disabilities to engage in tertiary education. This article explores the experiences of lecturers supporting students with Autism Spectrum Disorders (ASD) in a Malaysian tertiary education institute. Their views are vital as they are the first point of contact when academic support is needed. Interviews were conducted with six lecturers who had experience in teaching students with ASD. Data were analyzed using thematic analysis. The main findings suggest that these lecturers were restricted in supporting students with ASD due to issues related to knowledge and awareness, the specific educational needs of students with ASD, and the importance of student peers. Lecturers have limited knowledge to draw on when making decisions to support the needs of the students. Nevertheless, they acknowledged that some of the students' peers created a buddy system where they worked together with the lecturers to support the ASD students' needs in the absence of specialist personnel. The prospect of supporting and providing effective services to all students, regardless of background, ethnicity, gender and ability, is much anticipated by dedicated educators. This has implications for the way professionals are trained in the future.
\end{abstract}

Keywords Autism, Higher Education, Lecturer,
Malaysia

\section{Introduction and Background}

Education for students with disabilities has evolved worldwide over the last three decades [1]. Before this time, the majority of students with disabilities were segregated from mainstream education and educated in separated classrooms. Owing to global shifts in thinking around special education, policy and legislation have changed the schooling options for students with disabilities, resulting in the inclusion of students with diverse needs in mainstream educational settings. The United Nations Sustainable Development Goal 4 (SDG4) is aimed at ensuring quality inclusive education and promoting lifelong learning opportunities for all. Another goal to be achieved by 2030 is that all women and men must have equal access to technical, vocational, and higher education.

The increasing pressure to provide inclusive and equitable education and promote lifelong learning for all has enabled a growing number of individuals with disabilities to engage in tertiary education [2], [3]. This includes those with Autism Spectrum Disorder (ASD). Individuals with ASD experience difficulties in social 
communication and behavioral functioning [4]. The breadth of the spectrum means that individuals with ASD have different learning needs. Some of the characteristics of ASD are difficulties controlling repetitive behavior, aggressive behavior, anxiety, difficulty in following instructions, and a tendency to self-harm. They may also develop difficulties in sensory integration, fine motor skills, and language and communication. The neurodevelopmental nature of the disorder may also cause individuals with ASD to experience difficulties during the transition to tertiary education level [5].

To accommodate the enrolment of students with disabilities in mainstream educational settings, professional development for personnel who work with students with special needs has also been provided [6], [7]. For example, organizations such as [8] in the USA have developed 10 content standards for novice special education teachers. These comprise teachers' knowledge and skills in the foundational fields, development and characteristics of learners, individual learning differences, instructional strategies, learning environments and social interactions, communication, instructional planning, assessment, professional and ethical practice, and collaboration.

Although pre-service teacher education programs equip teachers with a wide-range of skills so that they can work effectively with students with disabilities, there is limited training for lecturers in tertiary education institutions [9]. The aim of this article is to present the perspectives of lecturers in a Malaysian tertiary education institute on their experiences with students with ASD. Their views are vital, as they are the first point of contact when academic support is needed. First, the provision of educational services for students with disabilities in Malaysian education system is described.

In Malaysia, the welfare of individuals with a disability is the responsibility of the Ministry of Education (MOE), Ministry of Higher Education (MOHE), and the Ministry of Women, Family and Community Development (MWFCD). The MWFCD provides services for children with severe and multiple disabilities in Community Based Rehabilitation Centers; however, these are not included in the formal education system [10]. The tertiary education system is centralized with only one ministry, the MOHE, responsible for all public and private tertiary education institutes. According to reference [11], Easy Access to Education states that students with disabilities are eligible for education in public or private institutions of higher learning, including training and vocational education. They are also encouraged to work at government agencies as part of the one percent policy [12].

Although education for students with disabilities in Malaysia began prior to its independence in 1957, formal training programs and accreditation and licensure for special education teachers only commenced in the 1980 s
[13]. The first accreditation in Special Education at degree level was established by the National University of Malaysia, locally known as 'Universiti Kebangsaan Malaysia' in 1996. The provision of high quality education for students with a disability is now considered a top priority [12]. Through inclusive Malaysian education programs, an increasing number of students with ASD are placed in mainstream classes and are given the chance to further their studies through access to the mainstream curriculum and examinations. Tertiary education institutes must be prepared to accept such students. The need for inclusive practices within higher education will increase, as more students with ASD successfully complete their schooling [14].

Experiences in higher education are crucial in preparing students for the reality of working life. Although the enrolment of students with ASD in tertiary education has increased, recent research in this area indicates they encounter difficulties adjusting to this setting. This is partly because individuals with ASD may experience low selfesteem and struggle to form new relationships [15]. Specific learning support which differs from that provided at school level is therefore crucial in ensuring they are able to graduate. Accessibility has emerged as the main theme among the barriers often faced by individuals with disabilities in tertiary education, including access to higher education, access to information, physical surroundings, assumptions of 'normality', and low level of disability awareness [16]. Research on positive university experiences among students with ASD reported university support, training for staff, access to learning materials, and mentorship programs as helping students adapt to these settings [14], [17].

Students with ASD have increasingly been attracted to the science, technology, engineering and math (STEM) field globally [18]. The trend is similar in Malaysia where strong support from the government has increased the number of students with ASD undertaking technical and vocational programs. Higher acceptance rates at technical and vocational tertiary education institutions means students need to be able to work in groups where collaboration and communication are among the most important skills. Although lecturers have technical knowledge regarding the content of the course, they lack specific pedagogy with respect to the needs of students with disabilities [19].

\section{Methodology}

The overarching research question guiding this qualitative study was "What are lecturers' experiences in teaching students with ASD?" To answer this question, a small sample of six lecturers at a private tertiary education institute offering technical programs was recruited. To 
describe a subgroup in depth and reduce a phenomenon to its essence, reference [20] recommends the use of homogeneous sampling. This means the participants have similar characteristics that will help to illustrate the issues under investigation. The selection of participants was thus based on their experience teaching two students identified as having ASD. The first student produced excellent academic results, while the other exhibited low academic performance. To elicit the information required, data were collected through individual semi-structured interviews [21]. Interview sessions were conducted face-to-face in a location convenient to the participants. Each interview lasted approximately 40 minutes.

All interviews were transcribed and the interviewer sent a copy of the transcription to the participants to verify its accuracy. Data were analyzed using thematic analysis to identify relevant themes [22]. A comparative analysis was conducted between participants that allowed broad themes to be drawn out for detailed discussion and further analysis. The data analysis followed reference [22] six 'phases of thematic analysis': familiarization with the data; generating initial codes; searching for themes; reviewing themes; defining and naming themes; writing the report. Data were analyzed in Malay and the findings then translated into English while striving to remain as close as possible to the original words used by the participants [23].

\section{Findings}

All participants are given pseudonyms to protect their identity. The characteristics of the participants are presented in Table 1. All have an educational background in the field of engineering. Except for Amy, five had industrial experience prior to teaching. None of the participants have family members with ASD except for Adam who has a 6-year-old niece with ASD. Four of the lecturers taught a student with ASD who is performing well academically. One taught a poor performing student with ASD and one lecturer taught both students with ASD.

Data were read several times and then compared to extract emerging themes. Topics and patterns in participants' responses were identified by looking for regularities and phrases [24]. If two or more responses within a question were similar, they were coded into a topic. Data were scrutinized by noting interrelationships and connections between topics for each theme.

Three main themes emerged from participants' responses regarding their experience with students with ASD. These were 'Knowledge and awareness', 'Specific educational needs' and 'Peers'. To describe the lecturers' experiences in depth, the findings within each theme are discussed. To contextualize the responses, each quotation includes a description of the participant's pseudonym, the student they taught, and their teaching experience in years.

Table 1. Participants' demographic information

\begin{tabular}{|c|c|c|c|c|c|c|}
\hline $\begin{array}{c}\text { Description of the } \\
\begin{array}{c}\text { ASD student } \\
\text { participants have } \\
\text { taught }\end{array}\end{array}$ & Participants & Gender & Age & $\begin{array}{c}\text { Highest } \\
\text { education level }\end{array}$ & $\begin{array}{c}\text { Teaching } \\
\text { experience } \\
\text { (years) }\end{array}$ & $\begin{array}{c}\text { Family } \\
\text { members with } \\
\text { ASD }\end{array}$ \\
\hline \multirow{2}{*}{$\begin{array}{c}\text { High academic } \\
\text { performance }\end{array}$} & Adam & Male & 35 & Master & 5 & Yes \\
\cline { 2 - 7 } & Ema & Female & 37 & Bachelor & 5 & No \\
\cline { 2 - 7 } & Din & Male & 38 & Master & 9 & No \\
\hline $\begin{array}{c}\text { Low academic } \\
\text { performance }\end{array}$ & Amy & Male & 39 & Doctoral & 8 & No \\
\hline $\begin{array}{c}\text { Both high and low } \\
\text { academic performance }\end{array}$ & Suri & Female & 37 & Bachelor & 8 & No \\
\hline
\end{tabular}




\subsection{Knowledge and Awareness}

Knowledge and awareness emerged as a theme in which participants expressed concern about the lack of information they had to support the ASD students they teach. Although five of the six lecturers taught the ASD student whose performance was excellent, all participants expressed similar comments, an example of which is as follows:

"We need a talk on autism... Give awareness to lecturers so that they have concerns about those with autism, how to support their needs, to facilitate our teaching and learning activities" (Ema, taught the high performing ASD student, 5 years teaching experience)

Although there is a higher rate of enrolment of students with ASD in tertiary education institutes, no training is provided for lecturers to prepare them. This means they have less information available to guide decisions supporting the needs of students, as is the case for Amy, who taught a student with low academic performance:

"At that time, I had no knowledge of autism, I didn't know if he had family problems or social problems. When I asked his classmate, they said he is usually like that" (Amy, taught the low performing ASD student, 6 years of teaching experience).

One of the participants who taught ASD students with both high and low academic performance thought that experience with individuals with ASD matters in helping build expectations:

"[we need to know] how to manage this student's behavior because we have no experience, so we cannot imagine how this student will behave" (Suri, taught both ASD students, 8 years of teaching experience).

Suri has been teaching for longer than Ema and Amy and her experience teaching both high and low performing students highlighted the importance of understanding the behavioral characteristics of individuals with ASD. This also suggests that including students with disabilities at the tertiary education institute opens up opportunities for staff to learn about ASD, despite the lack of in-house training provided by the university.

\subsection{Specific Educational Needs of ASD}

In addition to the importance of knowledge and awareness, another issue that repeatedly emerged from the data was the specific learning needs of the ASD students. Although a general description exists of high and low performing students with ASD, the lecturers acknowledged the specific characteristics of the students affect their experiences in class. In particular, all lecturers highlighted the different behavioral and emotional needs demonstrated by the students. Din and Ady taught the same ASD student twice:

\begin{abstract}
"The important thing is we want to control his emotions because a special student's emotions are easily disturbed, even slight pressure will disturb him. If he feels disturbed, he may do something that impacts his learning." (Din, taught the high performing ASD student, 9 years of teaching experience)
\end{abstract}

Din had the longest teaching experience of all the participants. Din did not realize the student had ASD when he first taught him. He acknowledged that such students are different from other students and raised the importance of specialist knowledge in supporting students with ASD more effectively. Whilst acknowledging that differences among students may lead to stigmatization, recognizing the specific characteristics of the students helped lecturers to adapt to their teaching approach, as argued by Ady:

"The lecturers here have technical knowledge, but they have less knowledge about education for those with autism. Maybe there are appropriate techniques or methods [to support the ASD student]" (Ady, taught the high performing ASD student, 8 years of teaching experience).

Ady is the only participant with a doctoral degree. Although knowledge and skills are important for lecturers to teach in the technical tertiary education institute, he realized that students with ASD require specific teaching methods so that they can be better understood and supported. At school level, these specific educational needs were primarily supported by special education teachers. There were no specialist personnel available to assist the lecturers. Therefore, lecturers have to be trained in both content and pedagogical skills and knowledge. Another lecturer described the different characteristics of her student as follows:

"Different from a typical student in terms of their conversation, action, or reaction. For example, when we ask a question or we try to interact with him, there is something different about him; we don't know what the thing is that makes him different, but he is not same as others" (Amy, taught the low performing ASD student, 6 years of teaching experiences.

Amy could not explain the differences between the students but recognized there are some atypical characteristics of the student she taught. Staff members need to develop opportunities to nurture friendships between students so that diversity can be addressed appropriately. The increasing pressure to include more students with disabilities in mainstream settings means that educational institutions will be increasingly diverse in the future. Developing friendships at tertiary education is vital for students with ASD to expand networking and build confidence and social capital. This is particularly important for these students as they often struggle with social and communication skills. 


\subsection{Peers}

The third theme that emerged from the analysis was 'Peers'. All participants acknowledged that it is not only lecturers who are facing difficulties supporting students with ASD. They also emphasized the importance of support from other students. Students with ASD felt more comfortable talking to other students instead of the lecturers:

“...he was rarely alone, he had a close friend who understood his attitude, so the way for us to understand the student with ASD is to ask his friend. His close friend, most trustworthy friend... when his classmates joke around with this ASD student, this student will defend him" (Adam, taught high performing ASD student, 5 years of teaching experience).

Identifying individuals who were close to the student with ASD was crucial in enabling the lecturer to obtain information about the student. Adam was observant enough to identify the person who could help him support his ASD student. The following example also indicates that other peers need to be educated about autism to avoid teasing and bullying.

"When they feel uncomfortable with the lecturer, at least they have friends. So, I'll make sure these students work in a group with someone who gets along well with them. Sometimes they did not answer my questions directly when I asked them, but I can refer to their friends." (Suri, taught both ASD students, 8 years of teaching experience).

Nurturing trust and respect may also facilitate interactions among peers which is necessary in technical courses where group work is often conducted. Having peers with whom students with ASD are comfortable is also helpful for the lecturers, as described in the following extract:

"In group work, I need to ensure that he is in the same group as his best friend or else the work is not done" (Adam taught the high performing ASD student, 5 years of teaching experience).

Although peers were recognized as an important support system for students with ASD, the lecturers also recognized that on some occasions, other peers were the reasons students with ASD experienced behavioral or emotional problems. They may then disrupt teaching and learning activities for the rest of the class and, more importantly, harm their own social and academic progress. Two of the lecturers talked about incidents that had happened in their class:

“...I was upset with some students in my class...the ASD student didn't like the situation when I was angry...before that I didn't know he was autistic. I noticed he got distressed, but I was not angry with him, I was angry with the others" (Ema, taught the high performing ASD student, 5 years teaching experience).

It is typical for students in Malaysia to be informed when they do something wrong in class. Although only a few students may be involved in the wrongdoing, the whole class will usually be reminded not to repeat this behavior. This forms part of life experiences with peers. The lecturer's lack of awareness about the sensitivity of an individual with ASD to an intense environment can trigger emotional distress. Suri described her experience as follows:

"One day I said, 'today we are going to do this practical, tomorrow we will have a practical test', he [student with ASD] went back to his table mumbling sadly 'why today, why today, tomorrow test'. He was talking to himself not to his friend. When I saw him like that, I asked him 'what's wrong?' but he ignored me and continued with his mumbling. Then his friend said, 'Ms. he has a sickness'. the ASD student heard this, and said 'I am not sick'."' (Suri, taught both ASD students, 8 years of teaching experience).

A change of routine in classes is a common experience in tertiary education. When this happens, lecturers often have to ensure students can adapt to the changes. In the above example, the lecturer tried to understand why the student was sad; however, his distress was caused by insufficient understanding of the strategies needed to introduce changes to individuals with ASD. The student's peers were also unhelpful because they did not have sufficient knowledge about ASD. The label 'sickness' mentioned by the peers upset the student even more and thus the labelling issue should be addressed accordingly.

\section{Discussion}

This article has argued there is immense value in listening to the lecturers' experiences as they are the first point of contact when academic support is needed in tertiary education. Previous research has reported the increasing enrolment of students with ASD in STEMrelated fields and our findings indicate a similar trend. Ensuring participation in tertiary education for all aligns with the SDG4 goal to promote lifelong learning opportunities for all. In line with higher enrolment, there is an increasing body of research on stakeholders' experiences supporting these students.

Our findings showed that the increased diversity in tertiary education classrooms was not accompanied by a transformation in the way learning environments are organized. Hence, insufficient support for the physical inclusion of individuals with ASD in the institute promotes their exclusion from lessons [25]. The lecturers reported struggling to support the needs of students as they lacked the knowledge and skills needed to manage their behavioral and emotional distress. At the same time, the inclusion of 
students with ASD alongside other students opens up opportunities for friendships in which students spend most of their time together and learn to understand each other's needs, despite not being taught by special education staff. Furthermore, the development of friendship creates a sense of belonging that in the long run becomes an internal motivation for students to negotiate their differences.

The fact that some characteristics of ASD are not easily visible, especially to those with limited knowledge and awareness of autism, often means that the needs of such students neglected or unnoticed [5]. The lecturers in this study were not informed about the condition of the students with ASD in their class and were therefore unaware of their specific needs. Those who taught the students more than once or met other individuals with ASD were found to have increased knowledge and awareness about their needs.

The content standards for teachers working in an inclusive setting in reference [8] are not adequate because there are no specialist personnel to support the lecturers. The establishment of a disability unit at tertiary education institutions may fill the gap in knowledge as disability experts can better support the staff members and students. In the absence of such support, proactive initiatives will be needed to ensure lecturers' skills and knowledge address the needs of the students [9].

Teaching strategies such as clear instructions, pacing, organizational skills, processing time, group work and motivation were often regarded as specific pedagogy but these skills are also needed for those without disabilities [26]. Skills learnt at tertiary education level such as learning to form new relationships, adapting to sudden changes in routine, and group work are all necessary to prepare students for employment and life in general. Investments in personal development at this level also have influence on individual's future endeavors [27]. The young adults of today are the citizens of tomorrow with all the rights and responsibilities to contribute to the 'people and planet' [28]. Ensuring they are able to participate fully in the learning environment is crucial in ensuring they benefit from these experiences. Access to higher education, access to information, physical surroundings, assumptions of 'normality', and disability awareness are all necessary components of the support provided for students with disabilities in tertiary education [16]. This study however, found that the tertiary education institute is still far from providing sufficient levels of support and that a concerted effort from all stakeholders is necessary to develop an inclusive learning environment.

This study also indicated that high academic performance is not the only important issue for lecturers at tertiary education level. Students are expected to be able to deal with challenges and collaborate with other peers to complete given tasks as part of a course. Lecturers who are aware of the difficulties ASD students face will be able to help them in their studies and ensure the students are not left out. Furthermore, identifying teaching approaches that do not help students learn will help lecturers support those with low academic performance. An awareness that students with ASD require several adjustments will prevent lecturers from underestimating their potential [29].

In class, lecturers play a key role in supporting the learning processes of students with ASD [17]. While the lecturers in this study rated themselves low in knowledge and awareness of ASD, it was clear that collaboration with other students had helped them discover strategies to understand the needs of students with ASD better. Dedicated lecturers often want to ensure they are employing the appropriate teaching strategy for student with specials needs [30].

Characteristics of ASD such as sensory integration problems and sensitivity to changes are not easily addressed [26]. This study found that the lecturers were worried they did not have sufficient knowledge on behavior modification to meet the needs of ASD students who exhibited unexpected behavioral as well as emotional distress. A way forward to address this issue is to celebrate differences and learn to tolerate each other. Some of the students' peers were able to create a buddy system where they worked together to support each other's needs. This is important as friendships may not always develop, even if the students sit next to each other. Lecturers need to ensure an actual buddy system is allocated to every student so they can learn to support each other, which is in line with the wider agenda to develop an inclusive society [31].

\section{Conclusions}

The main findings of this study suggest that the lecturers at a tertiary education institute were restricted in supporting students with ASD due to issues related to knowledge and awareness, the specific educational needs of students with ASD, and the importance of student peers. Increasing enrolment of students with ASD has not been accompanied by sufficient training for staff members to adequately support the needs of these students. Effective inclusion of students with ASD in tertiary education institutes will require inter-ministerial collaboration, as well as a stepchange in the awareness of professionals regarding disability equality in education.

In recent years, the Malaysian government has proclaimed its commitment to support the education of individuals with disabilities in tertiary education. However, limited expertise in guiding practices means it is unlikely the implementation of inclusion can be effectively achieved in the immediate future. The fact that the majority of students with disabilities are educated in separate educational settings at school level presents considerable barriers to their inclusion at tertiary education level. This study confirms the complexity inherent in ensuring the right of everyone to inclusive education.

A key strength of this study lies in its focus on the 
experiences of lecturers teaching students with ASD. However, the study was small in scale, given the diversity of tertiary education settings in Malaysia. More research is, therefore needed to understand how students with ASD experience tertiary education and the outcomes of their experiences. It has implications for developing suitable training for professionals in the future.

\section{Acknowledgement}

The study was supported by a grant from the Faculty of Education, Universiti Kebangsaan Malaysia, PP-FPEND2020 and GG-2019-003.

\section{REFERENCES}

[1] M. Ainscow, A. Dyson, and S. Weiner, "From exclusion to inclusion: A review of international literature on ways of responding to students with educational needs in schools," En-clave pedagógica Rev. Int. Investig. e Innovación Educ., vol. 13, pp. 13-30, 2013.

[2] M. Fabri, G. Fenton, P. Andrews, and M. Beaton, "Experiences of higher education students on the autism spectrum: Stories of low mood and high resilience," Int. J. Disabil. Dev. Educ., pp. 1-19, 2020.

[3] N. Toor, T. Hanley, and J. Hebron, "The facilitators, obstacles and needs of individuals with Autism Spectrum Conditions accessing further and higher education: a systematic review," J. Psychol. Couns. Sch., vol. 26, no. 2, pp. 166-190, 2016.

[4] S. T. Johansson, "'He is intelligent but different': Stakeholders' perspectives on children on the autism spectrum in an urban Indian school context," Int. J. Disabil. Dev. Educ., vol. 61, no. 4, pp. 416-433, 2014.

[5] S. M. Zeedyk, Y. Bolourian, and J. Blacher, "University life with ASD: Faculty knowledge and student needs," Autism, vol. 23, no. 3, pp. 726-736, 2019.

[6] P. T. Sindelar, M. T. Brownell, and B. Billingsley, "Special education teacher education research: Current status and future directions," Teach. Educ. Spec. Educ. J. Teach. Educ. Div. Counc. Except. Child., vol. 33, no. 1, pp. 8-24, Feb. 2010.

[7] M. J. A. del Olmo Fernández, M. J. S. Villalba, and J. J. L. Olivencia, "Perceptions of professors of educational inclusion: Diversity, cooperation and commitment," Univers. J. Educ. Res., vol. 8, no. 8, pp. 3562-3569, 2020.

[8] Council for Exceptional Children, "Content standards for beginning special education teachers.," Council for exceptional children, 2009. [Online]. Available: http://www.cec.sped.org.

[9] E. Ponomaryova, H. G. Guterman, N. Davidovitch, and Y. Shapira, "Should lecturers be willing to teach highfunctioning autistic students: What do they need to know?,"
High. Educ. Stud., vol. 8, no. 4, pp. 35-45, 2018.

[10] Z. M. Jelas and M. M. Ali, "Inclusive education in Malaysia: Policy and practice," Int. J. Incl. Educ., vol. 18, no. 10, pp. 1-13, Jul. 2020.

[11] Laws of Malaysia, "Persons with Disabilities Act." Laws of Malaysia, Kuala Lumpur, 2008.

[12] Ministry of Education, Malaysia Education Blueprint 20132025. Putrajaya: Ministry of Education, 2013.

[13] M. N. Awang Mat, "Developing special education in each country and enhancing international mutual cooperation among countries in the Asia-Pacific region.," in 21st APEID Regional Seminar on Special Education, 2001, pp. 69-82.

[14] A. Moriña, "Inclusive education in higher education: challenges and opportunities," Eur. J. Spec. Needs Educ., vol. 32, no. 1, pp. 3-17, 2017.

[15] G. Grogan, "Supporting students with autism in higher education through teacher educator programs," vol. 24 , no. 2, pp. 8-13, 2015.

[16] A. S. Amin, S. Z. M. Zuki, and N. M. Akhir, "Accessibility to facilities for persons with disabilities at public institutes of higher learning," Int. J. Recent Technol. Eng., vol. 8, no. 2 Special Issue 10, pp. 21-37, 2019.

[17] V. M. Molina, V. H. Perera Rodríguez, N. Melero Aguilar, A. Cotán Fernández, and A. Moriña, "The role of lecturers and inclusive education," J. Res. Spec. Educ. Needs, vol. 16, pp. 1046-1049, 2016.

[18] X. Wei, E. R. A. Christiano, J. W. Yu, J. Blackorby, P. Shattuck, and L. A. Newman, "Postsecondary pathways and persistence for STEM versus non-STEM majors: Among college students with an autism spectrum disorder," $J$. Autism Dev. Disord., vol. 44, no. 5, pp. 1159-1167, 2014.

[19] L. M. Tahir, N. Q. Mustafa, and M. H. M. Yassin, "Pendidikan teknik dan vokasional untuk pelajar berkeperluan khas," J. Pendidik dan Pendidik., vol. 24, 2009.

[20] J. W. Creswell, Educational Research: Planning, conducting and evaluating quantitative and qualitative research, Fourth. Boston: Pearson Education, 2012.

[21] S. Kvale and S. Brinkmann, Interviews: Learning the craft of qualitative research interviewing, $2 \mathrm{nd}$ ed. Thousands Oaks: Sage Publications, 2009.

[22] V. Braun and V. Clarke, "Thematic Analysis," APA Handb. Res. Methods Psychol. Vol. 2, vol. 2, pp. 57-71, 2012.

[23] P. J. Larkin, B. Dierckx de Casterlé, and P. Schotsmans, "Multilingual translation issues in qualitative research: Reflections on a metaphorical process.," Qual. Health Res., vol. 17, no. 4, pp. 468-76, Apr. 2007.

[24] R. C. Bogdan and S. K. Biklen, Qualitative research for education: an introduction to theory and methods, 5th ed. Pearson, 2007.

[25] Y. Sayed, Exclusion and inclusion in the south with reference to education: A review of the literature. Sussex: Department for International Development, 2002.

[26] E. Gurbuz, M. Hanley, and D. M. Riby, "University Students 
with Autism: The Social and Academic Experiences of University in the UK," J. Autism Dev. Disord., vol. 49, no. 2, pp. 617-631, 2019.

[27] I. Shyle, "The role of the higher education institutions in the career development of Albanian students," Univers. J. Educ. Res., vol. 8, no. 5, pp. 2117-2122, 2020.

[28] UNESCO, Education for people and planet: Creating sustainable future for all. Paris: UNESCO, 2016.

[29] R. Y. Cai and A. L. Richdale, "Educational experiences and needs of higher education students with autism spectrum disorder," J. Autism Dev. Disord., 2015.

[30] Z. Saadi and M. Mohd Ali, "Kesediaan dan penerimaan para pengajar terhadap mahasiswa mahasiswi berkeperluan khas di Institusi Pengajian Tinggi," Fak. Pendidikan, Univ. Kebangs. Malaysia, 2008.

[31] Y. Yusof, C. C. Chan, A. H. Hillaluddin, F. Z. Ahmad Ramli, and Z. Mat Saad, "Improving inclusion of students with disabilities in Malaysian higher education," Disabil. Soc., vol. 0 , no. 0 , pp. 1-26, 2019. 